\title{
INVESTIGATION OF ELECTROMAGNETIC CHARACTERISTICS OF FERRO-VORTEX APPARATUS
}

\author{
Andrey Adoshev, Sergey Antonov, Alexander Ivashina, Sergey Yastrebov \\ Stavropol State Agrarian University, Russia \\ adoshev@mail.ru, antonov_serg@mail.ru,av_ivashina49@mail.ru, yastrsergej@yandex.ru
}

\begin{abstract}
The ferro-vortex apparatus relates to devices for electro-mechanical processing liquid, bulk and other blends that can be used in agriculture, medicine, chemical, oil and gas industry, communal services and other areas. The article presents the sequence of experimental studies of the electromagnetic characteristics of the ferro-vortex apparatus on the bench designed for this purpose. The parameters consumed by the device from the network of electrical energy were measured. In the course of the experiment, with the help of applied programs oscillograms of the currents in the windings of the inductor magnetic core of the ferro-vortex apparatus have been received, depending on the size of the operating clearance and the weight of the ferromagnetic particles in the working area. In addition, the universal portable milli-teslameter measured the mean-rectified value of the magnetic induction of the alternating magnetic field on the area "B" of the working area of the device, in the absence of ferromagnetic particles in it. The values of magnetic induction were measured at the control points near the surfaces of the magnetic inductor core and the axial magnetic core, incrementally increasing the distance between them. On the basis of the experimentally obtained values of magnetic induction on the site "B" of the working area of the apparatus, curves were constructed, limiting the region of dependence of the magnitude of the induction coefficient in the gap on the gap size. The article shows that the ferro-vortex apparatus is a three phase symmetrical load, so to connect it to a symmetrical network does not degrade the quality of electricity. The sequence of selection of the value of the calculated magnetic induction in the gap was determined.
\end{abstract}

Keywords: ferro-vortex apparatus, working zone, working gap, induction coefficient.

\section{Introduction}

Ferro-vortex apparatus (FVA) is a device of a new type that uses the energy of a rotating electromagnetic field to intensify technological processes [1;2]. Energy conversion in FVA occurs in the working gap $(\delta)$ of the working chamber, where the main part of the magnetic field energy is concentrated.

In FVA, the processed materials are subjected to complex effect, which includes intensive mixing and dispersion, acoustic and electromagnetic processing, friction, local pressures, electrolysis, etc.

FVA uses the energy of a rotating electromagnetic field with a high specific concentration per unit volume of the working area. Under the influence of the field in the working area, the components are very quickly and thoroughly mixed and activated. Due to this, physical-chemical and mechanicalphysical reactions and, accordingly, derivative processes are accelerated hundreds and thousands of times, as a result of which the productivity of technological lines is increased [3-6]. In comparison with many traditional technologies and installations, the specific energy consumption and metal consumption are often reduced hundreds of times.

Properly selected operating gap largely determines the energy performance of the device [1; 712]. The less $\delta$, the less its magnetic resistance and magnetic voltage, which is the main part of the total magnetomotive force (MMF) of the magnetic circuit of the entire apparatus. Therefore, a decrease in $\delta$ leads to a corresponding decrease in the MMF of the magnetic circuit and the magnetizing current of the apparatus, thereby increasing its $\cos \varphi$ and reducing losses in the inductor winding. In this case, the value $\delta$ is determined by the performance of the apparatus, the pump capacity and the mass of ferromagnetic particles (FMP) $(m)$ in the working area during operation of the apparatus to ensure a continuous process to control and eliminate the possibility of stagnation of the processed material in the working area [1].

In the process of selecting the design parameters of the FVA [13] there is a need to produce prototypes, which is associated with high time and material costs. To reduce costs, it is necessary to determine the sequence of calculation of the most important electromagnetic characteristics of the device. 


\section{Materials and methods}

Calculation of the parameters of the inductor of the initial model FVA [1;2] was carried out using the technique used for axial asynchronous electric motors of medium and low power $(\delta=0.5-1 \mathrm{~mm})$ [7-9; 13].

FVA with the parameters of the inductor magnetic circuit and the axial magnetic circuit calculated by the proposed method (at $\delta=40 \mathrm{~mm}$ ), has a value of magnetic induction in the working gap $\left(B_{\delta}\right)$ below the recommended (0.15-0.2 T) [3]. The value of the magnetizing current exceeds the nominal current by 1.5-3 times, despite the correctly selected dimensions and low saturation of the magnetic circuit. This is due to the large value of the magnetic voltage of the working gap, which is typical for the apparatus of vortex layer (AVS) of low power.

After the manufacture of the apparatus, experimental studies of its electromagnetic characteristics were carried out. For this purpose, a stand was developed, the block diagram of which is presented in Fig. 1.

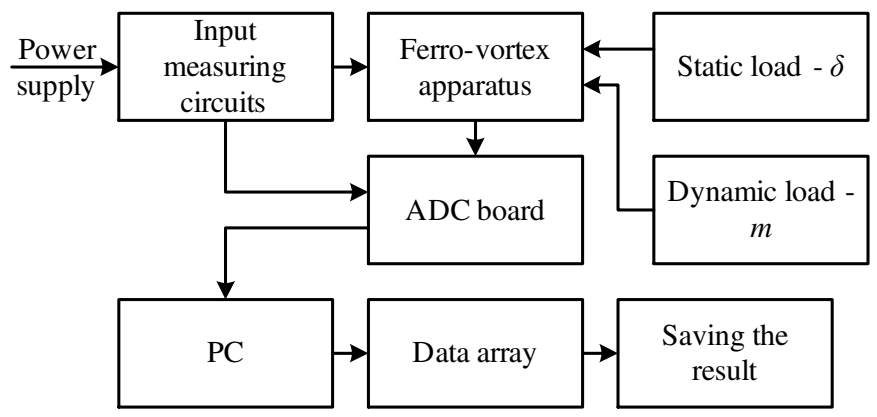

Fig. 1. Block diagram of experimental stand

Parameters consumed by the FVA from the electrical network of electrical energy are measured by a set of measuring devices K-540. The magnitude of the measured current completely corresponds to the calculated at $\delta=1 \mathrm{~mm}$ [1].

The current in the FVA windings was measured depending on the value $\delta$ of the working chamber (at $m=0$, Fig. 2, a) and the mass of the FMP in the working area ( $m$, at $\delta=40 \mathrm{~mm}$, Fig. 2, b).

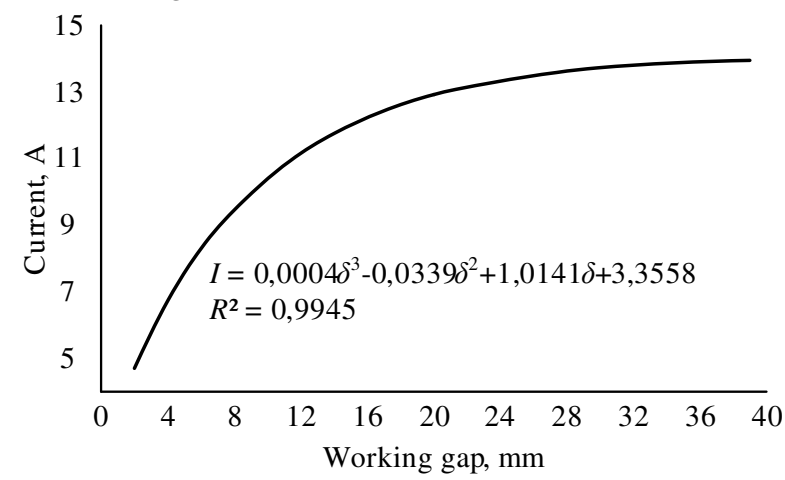

a)

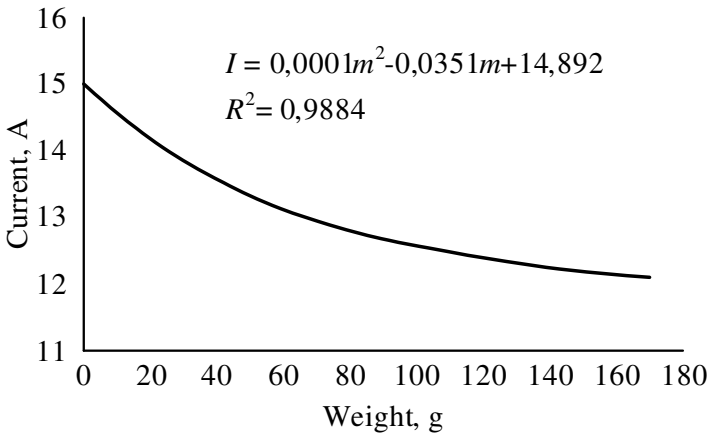

b)

Fig. 2. Graph of current dependence in FVA windings from: a - size of the working gap; $\mathrm{b}$ - mass of the FMP in the working area

Registration of electromagnetic characteristics was carried out using the ADC Board L-264 (Fig. 1), which is a reliable device for input and processing of analog and digital information with a personal computer.

Software for board L-264 consists of a program GeMiS Oscilloscope and GeMiS Win. GeMiS Oscilloscope - provides continuous registration of signals using ADC, displaying the form and spectrum of the signals on the computer screen in real time, saving the recorded data to a file. GeMiS Win - allows you to display report arrays registered with the GeMiS Oscilloscope in the form of graphs, process source data in the time and frequency domains, filter, smooth, and other functions, as well as export files to ASCII text format for further mathematical processing with a table editor MS Excel. 
During the experiment, with the help of application of the programs GeMiS Oscilloscope and GeMiS Win were recorded oscillograms of currents in the windings of the magnetic circuit inductor FVA (Fig. 1) depending on the value $\delta(m=0$, Figures 3,4$)$ and the mass of the FMP in the working area $(\delta=40 \mathrm{~mm}$, Figures 5,6$)$.

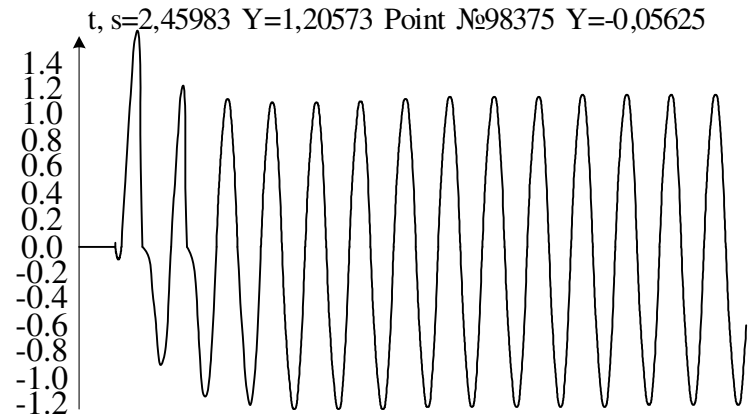

a)

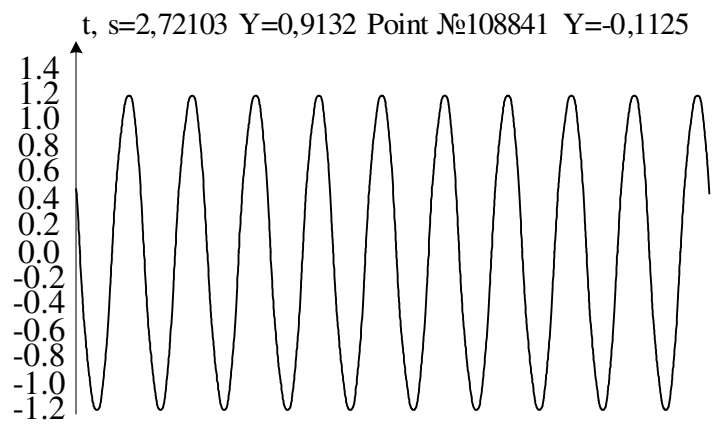

b)

Fig. 3. Oscillograms of currents in windings of FVA depending on size of working gap $(\boldsymbol{m}=\mathbf{0}, \boldsymbol{\delta}=\mathbf{3} \mathbf{~ m m})$ : a - start mode; $\mathrm{b}$ - working mode

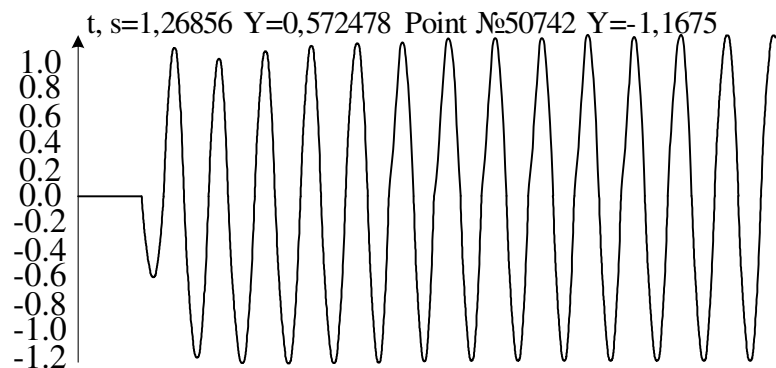

a)

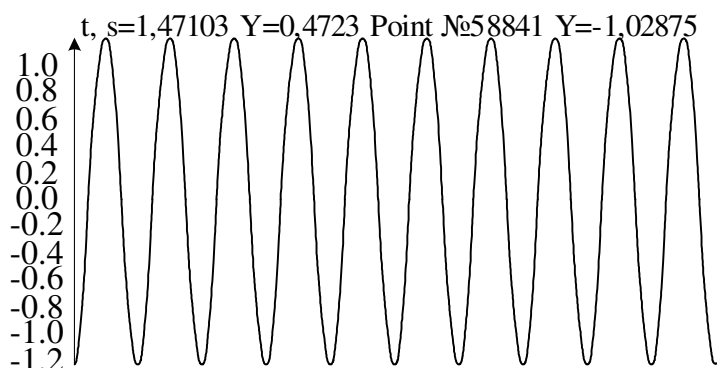

b)

Fig. 4. Oscillograms of currents in windings of FVA depending on size of working gap $(\boldsymbol{m}=\mathbf{0}, \boldsymbol{\delta}=\mathbf{4 0} \mathbf{~ m m})$ : a - start mode; b - working mode

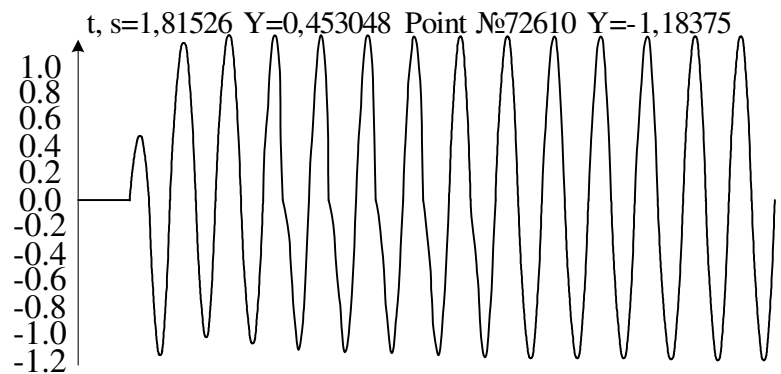

a)

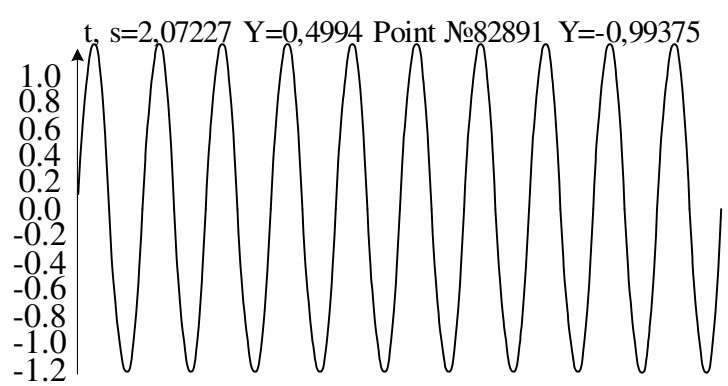

b)

Fig. 5. Oscillograms of currents in windings of FVA depending on mass of FMP in working area $(\delta=40 \mathrm{~mm}, \boldsymbol{m}=\mathbf{5 0} \mathrm{g})$ : $\mathrm{a}$ - start mode; $\mathrm{b}$ - working mode

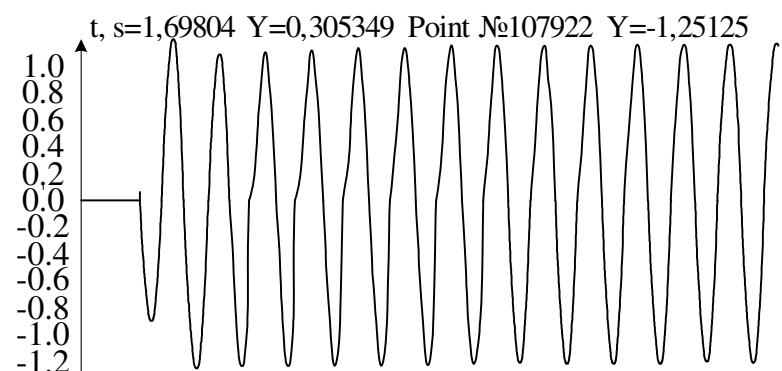

a)

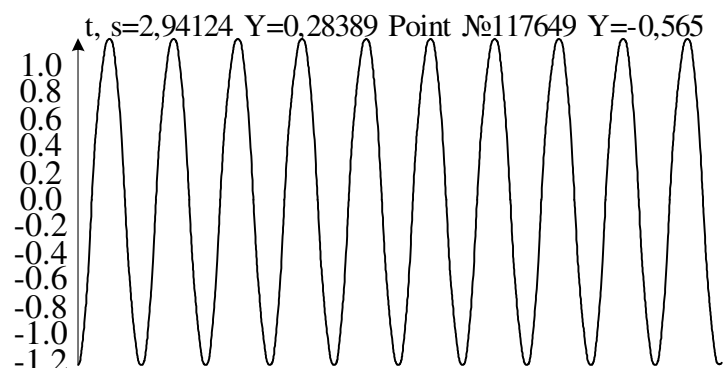

b)

Fig. 6. Oscillograms of currents in windings of FVA depending on mass of FMP in working area $(\delta=40 \mathrm{~mm}, \boldsymbol{m}=\mathbf{1 5 0} \mathrm{g})$ : a - start mode; b - working mode 
An important condition for the efficiency work of the vortex layer FMP and, consequently, FVA is the uniformity of the magnetic field on the site " $\mathrm{B}$ " of the working zone [1;2]. One of the main parameters of the magnetic field of FVA is the value of magnetic induction at idle, i.e. subject to the absence of FMP [3; 4]. The value of the induction determines the speed of mixing and dispersion of phases, as well as the speed of the chemical reaction in the zone of the vortex layer of FMP.

In the course of the experiment the values $B_{\delta}$ on the site "B" working area of FVA were measured, in the absence of FMP in it.

The values of $B_{\delta}$ were measured at the control points (Fig. 7) at the surfaces of the inductor of the magnetic circuit and the axial magnetic circuit, incrementally increasing the distance between them. Since the axial magnetic circuit is made without slots and windings, all control points were projected onto its surface from the surface of the inductor tine of the magnetic circuit $[1 ; 13]$.

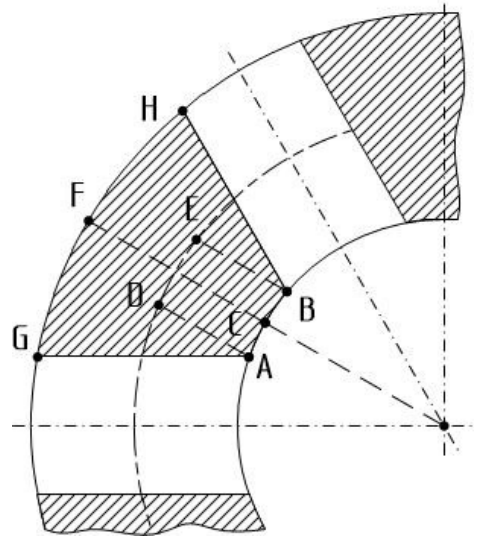

Fig. 7. Scheme of arrangement of control points

Table 1 presents the averaged measuring values $B_{\delta}$.

Table 1

Value of $B_{\delta}(\mathrm{mT})$ at the control points at different values of $\delta$

\begin{tabular}{|c|c|c|c|c|c|c|c|c|c|}
\hline \multirow{2}{*}{$\delta, \mathbf{m m}$} & \multicolumn{8}{|c|}{ Control points } & \multirow{2}{*}{$\begin{array}{c}\text { Average } \\
\text { value }\end{array}$} \\
\hline & $\mathbf{A}$ & B & $\mathrm{C}$ & D & $\mathbf{E}$ & $\mathbf{F}$ & $\mathbf{G}$ & H & \\
\hline 3 & 300 & 295 & 325 & 510 & 505 & 440 & 420 & 435 & 403.75 \\
\hline 6 & 255 & 250 & 275 & 430 & 427.5 & 370 & 355 & 367.5 & 341.25 \\
\hline 9 & 220 & 217.5 & 240 & 372.5 & 370 & 320 & 307.5 & 320 & 295.94 \\
\hline 12 & 190 & 190 & 210 & 325 & 320 & 277.5 & 267.5 & 280 & 257.5 \\
\hline 15 & 175 & 172.5 & 190 & 295 & 290 & 252.5 & 245 & 255 & 234.38 \\
\hline 18 & 160 & 157.5 & 175 & 270 & 265 & 230 & 225 & 232.5 & 214.38 \\
\hline 21 & 147.5 & 145 & 160 & 247.5 & 245 & 212.5 & 207.5 & 215 & 197.5 \\
\hline 24 & 137.5 & 135 & 150 & 230 & 227.5 & 197.5 & 192.5 & 200 & 183.75 \\
\hline 27 & 130 & 127.5 & 140 & 215 & 212.5 & 185 & 180 & 187.5 & 172.19 \\
\hline 30 & 122.5 & 120 & 132.5 & 202.5 & 200 & 175 & 170 & 177.5 & 162.5 \\
\hline 33 & 117.5 & 115 & 127.5 & 192.5 & 190 & 167.5 & 162.5 & 170 & 155.31 \\
\hline 36 & 112.5 & 110 & 122.5 & 185 & 182.5 & 162.5 & 157.5 & 165 & 149.69 \\
\hline 39 & 110 & 107.5 & 120 & 180 & 177.5 & 157.5 & 155 & 160 & 145.94 \\
\hline 42 & 107.5 & 105 & 117.5 & 177.5 & 175 & 155 & 152.5 & 157.5 & 143.44 \\
\hline 45 & 105 & 102.5 & 115 & 175 & 172.5 & 152.5 & 150 & 155 & 140.94 \\
\hline 48 & 102.5 & 100 & 112.5 & 172.5 & 170 & 150 & 147.5 & 147.5 & 137.81 \\
\hline
\end{tabular}

\section{Results and discussion}

The results of the current measurement depending on the size $\delta$ of the working chamber and the mass of the FMP in the working zone showed that the current value increases in increasing the distance between the inductor magnetic core and the axial magnetic core $(\delta)$ and decreases in increasing the mass of the FMP in the working zone (Fig. 2). 
With the help of MS Excel the lines of trend (graphs of the approximating function) - curves (straight) lines approximating the initial data based on the regression equation are constructed. The equations of the trend lines on the charts (Fig. 2, a, b) are obtained with a high level of approximation $\left(R^{2}=0.9945, R^{2}=0.9884\right)$, which indicates the adequacy of the mathematical description of these dependencies.

FVA is a three-phase symmetric load (currents in phases are equal). Therefore, connecting it to a symmetrical network does not worsen the quality of electric power (Figures 3-6).

Experimentally obtained values $B_{\delta}$ (table 1 ) served as the basis for constructing the curves that limit the dependence area of the coefficient of induction in the gap $\left(k_{B \delta}\right)$ from the value of $\delta$ (Fig. 8) (calculation of the parameters of the magnetic core initial model of FVA was made at $B_{\delta}=1 \mathrm{~T}$ and $\delta=1 \mathrm{~mm})[1 ; 13]$.

On the basis of the experimental data on the use of AVS in technological processes, the expedient interval $B_{\delta}-0.1-0.2 \mathrm{~T}$ was determined [3]. Therefore, the value that determines the efficiency of the FVA is the required (actual) value of magnetic induction in the working gap $-B_{\delta \text { fact }}$.

With the help of MS Excel for the trend line of the average value of magnetic induction in the working gap $\left(B_{\delta}\right)$ in the area "B" of the working zone of the FVA equation was obtained (Fig. 8) with a high level of approximation $\left(R^{2}=0.99\right)$, which indicates the adequacy of the mathematical description of these dependencies.

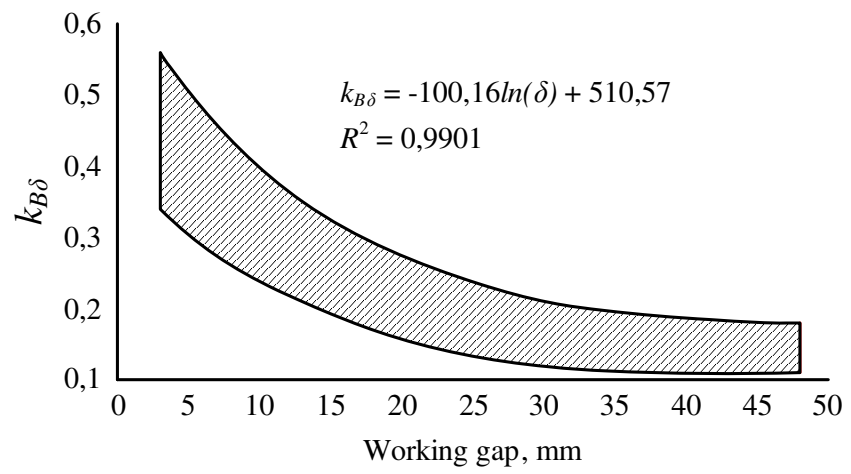

Fig. 8. Area of dependence of induction coefficient in working gap on gap value

The size of the working gap in the FVA is much more than air gaps in standard electric machines cylindrical and axial execution. Therefore, in the calculations of FVA, you should use the value of the calculated magnetic induction in the working gap $\left(B_{\delta . c a l c}\right)$, equal to the ratio of the required (actual) value of the induction in the gap $\left(B_{\delta . f a c t}\right)$ to the coefficient of induction in the gap $\left(k_{B \delta}\right)$ depending on $\delta$ (selected from the area bounded by the curves built on the basis of the experiments (Fig. 8)).

\section{Conclusions}

1. The amplitude of the starting current is insignificant and exceeds the amplitude of the rated current by no more than $36 \%$ both when the gap changes and the FMP mass changes in the working area.

2. Harmonics of higher orders appear only at start-up, and the duration of their manifestation does not exceed 10 periods. In the operating mode harmonics of higher orders are not manifested.

3. The connection of the FVA to the symmetrical network does not worsen the quality of electric power.

4. On the basis of the experimentally obtained values of the magnetic induction $\left(B_{\delta}\right)$ on the site "B" of the working zone of FVA, curves were built bounding the area of dependence of the coefficient of induction in the gap $\left(k_{B \delta}\right)$ by the size of the working gap $(\delta)$.

5. In the calculation of FVA you should use the value of the calculated magnetic induction in the working gap $\left(B_{\delta . c a l c}\right)$, equal to the ratio of the actual (required) induction in the gap $\left(B_{\delta . \text { fact }}\right)$ to the coefficient of induction in the gap $\left(k_{B \delta}\right)$. 


\section{References}

[1] Адошев А. И. Ферровихревой аппарат для обеззараживания жидкого свиного навоза (Тhe ferro-vortex apparatus for disinfection of liquid pig manure): dis.... cand. tech. sciences: Stavropol, 2011. 191 p. (In Russian).

[2] Ferro-vortex apparatus / Adoshev A., Antonov S., Yastrebov S., Melnikov M. // Materials of the of 16th International Scientific Conference "Engineering for rural development", 2017. Volume 16. РP 804-810.

[3] Логвиненко Д.Д., Шеляков О.П. Интенсификация технологических процессов в аппаратах вихревого слоя (Intensification of technological processes in apparatus of the vortex layer). Kiev: Technique, 1976. $143 \mathrm{p}$.

[4] Вершинин, Н.П. Установки активации процессов. «Использование в промышленности и в сельском хозяйстве. Экология» (The device of activation of processes. "A use in industry and in agriculture. Ecology"). Rostov-on-Don, 2004. 314 p. (In Russian).

[5] WIPO Patent Application WO/2007/114731 A1, B01J 19/12. Process activation unit. Available at https://patentscope.wipo.int/search/ru/detail.jsf?docId=WO2007114731 Received for publication October 24, 2006. Accepted after corrections October 11, 2007.

[6] Wołosiewicz-Głab M. Construction of the electromagnetic mill with the grinding system, classification of crushed minerals and the control system / Wołosiewicz-Głab M., Ogonowski S., Foszcz D. // 17th IFAC Symposium on Control, Optimization and Automation in Mining, Mineral and Metal Processin. 2016, Volume 49, Issue 20. pp. 67-71.

[7] Игнатов В.А. Исследование распределения магнитного поля в активном объеме торцевых электрических машин с витым магнитопроводом (Investigation of the distribution of the magnetic field in the active volume of butt-end electrical machines with a twisted magnetic circuit). Electrical engineering, 1983, No. 8. pp. 27-30. (In Russian).

[8] Игнатов В.А., Вильданов К.Я. Торцевые асинхронные электродвигатели интегрального изготовления (Butt-end asynchronous electric motors of the integral making). Moscow: Energoatomizdat, 1988. 301 p. (In Russian).

[9] Копылов И.П., Маринин Ю.С. Тороидальные двигатели (Toroidal engines). Moscow: Energy, 1971. 197 p. (In Russian).

[10]Проектирование электрических машин: учебник для вузов / под ред. И.П. Копылова (Designing of electrical machines: textbook for universities). Moscow: High school, 2005. 767 p. (In Russian).

[11]Логвиненко Д.Д., Шеляков О.П., Польщигов Г.А. Определение основных параметров аппаратов с вихревым слоем (Determination of the main parameters of the apparatus with a vortex layer). Chemical and petroleum engineering, 1974, No. pp. 17-23. (In Russian).

[12] Казанский В.М., Зонов В.Н., Британчук В.М. К вопросу о сравнении асинхронных электродвигателей торцевого и цилиндрического исполнения малой мощности (То the question about comparison of asynchronous electric motors of butt-end and cylindrical execution of small-yield). Asynchronous micromachines. Materials interuniversity scientific conference. Kaunas, 1969. pp. 212-216.

[13] Адошев А.И., Ивашина А.В. Особенности расчета индуктора ферровихревого аппарата (Features of calculation of the inductor of ferro-vortex apparatus). Methods and means of increase of efficiency of use of electrical equipment in industry and agriculture: collection of scientific works. Stavropol, 2010. pp. 8-13. (In Russian). 